\title{
Pediatric News
}

\section{LUEDTKE NAMED 2014 HELMS RECIPIENT}

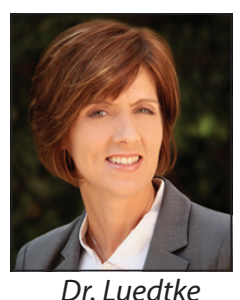

Dr. Luedtke is one of the founding faculty members of the Texas Tech University Health Sciences Center (TTUHSC) School of Pharmacy and is an Associate Professor of Pharmacy Practice. Dr. Luedtke received her Bachelor of Science and Doctor of Pharmacy degrees from the University of Wisconsin (1994). She completed her practice residency at Meriter Hospital in Madison, Wisconsin (1994) and pediatric specialty residency at the University of Kentucky Children's Hospital (1995).

Dr. Luedtke's area of practice interest is in neonatology. She has practiced as a clinical specialist providing clinical pharmacy services in neonatology at Northwest Texas Children's Hospital for over 15 years. Dr. Luedtke has developed neonatal pharmacotherapy educational programs for PPAG, ASHP, and the National Neonatal Nurses Conferences. She has been an invited speaker for national and regional meetings and has authored numerous book chapters and manuscripts on pediatric pharmacotherapy. Her honors recognizing clinical and teaching excellence include: PPAG Fellow Recognition (2011),TTUHSC President's Distinguished Clinician Award (2005), TTUHSC School of Pharmacy Most Influential Professor Award (2004, 2005), Texas Society for Health Systems Pharmacists Best Practice Award (2003), PPAG Best Practice Award (2002), and Texans Caring for Texans Award (2001, 2003). She is a reviewer for several medical and pharmacy journals and is on the editorial board for two pharmacy journals. Research interests include neonatal pharmacotherapy and education. Dr. Luedtke has been dedicated to the education of future pediatric practitioners having established the Pediatric Specialty Residency at TTUHSC School of Pharmacy in 1999. One of her proudest accomplishments is to have mentored outstanding practitioners who have become young leaders in the area of pediatric pharmacy.

Dr. Luedtke has been a committed member to PPAG since 1995. She began her service to PPAG with her work on the Education Committee and subsequently has been involved at all levels including the Advocacy Committee, Board of Directors, and service as a Past President. She currently serves as the Associate Editor for the Journal of Pediatric Pharmacology and Therapeutics.

\section{PPAG WELCOMES JENNIFER CHOW}

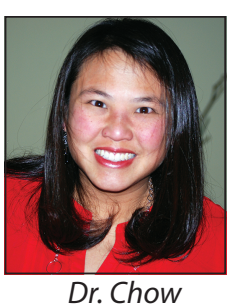

Jennifer W. Chow, PharmD has joined PPAG as a consultant for educational programming. In her role she will assist with planning Continuing Education programs and events, including the Annual Conference, webinars, and Prep Courses for Board

Certification.

Dr. Chow is a Pediatric Clinical Pharmacy Specialist. She earned a Bachelor of Science degree from Christian Brothers University in 2000 and her Doctorate of Pharmacy from the University of Tennessee College of Pharmacy in Memphis in 2005. She completed a residency in pediatric pharmacotherapy at Le Bonheur Children's Hospital and the University of Tennessee College of Pharmacy in 2006.

After completing her residency, Jennifer was the General Pediatrics Clinical Specialist for the Children's Hospital of The King's Daughters in Norfolk, VA. She helped develop and was the director of the pharmacist-run RSV Prevention Clinic. She continues to work with CHKD as an independent consultant. Jennifer has been a member of PPAG since 2005. She has presented poster presentations, been a presenter at PPAG Annual Conferences and received PPAG Best Practice Awards.

\section{FDA APPROVAL OF VIMIZIM (ELOSULFASE ALFA) FOR TREATMENT OF PATIENTS WITH MUCOPOLYSACCHARIDOSIS TYPE IVA (MPS IVA, MORQUIO A SYNDROME)}

On February 14, 2014, FDA approved VIMIZIM, 
the first FDA-approved treatment for patients with MPS IVA. MPS IVA is characterized by the absence or marked reduction in lysosomal enzyme $\mathrm{N}$-acetylgalactosamine-6-sulfatase (GALNS) activity, leading to accumulation of glycosaminoglycans keratan sulfate and chondroitin-6-sulfate in cells throughout the body causing widespread cellular, tissue, and organ dysfunction. VIMIZIM is a recombinant form of human GALNS. It is intended to provide the exogenous enzyme for uptake into the lysosomes via the mannose-6-phosphate receptors (M6PR). The recommended dose of VIMIZIM is $2 \mathrm{mg}$ per $\mathrm{kg}$ body weight administered once every week as an intravenous (IV) infusion over a minimum of 3.5 to 4.5 hours, based on infusion volume.

The safety and efficacy of VIMIZIM were assessed in a 24-week, randomized, double-blind, placebo-controlled clinical trial of 176 patients with MPS IVA. The age of patients ranged from 5 to 57 years. Patients received VIMIZIM $2 \mathrm{mg} / \mathrm{kg}$ once every week ( $Q W, n=58), 2 \mathrm{mg} / \mathrm{kg}$ once every other week (QOW, $n=59)$, or placebo $(n=59)$. The primary efficacy endpoint was the change from baseline in the distance walked in 6 minutes. At Week 24, patients in the $2 \mathrm{mg} / \mathrm{kg}$ QW treatment group demonstrated greater treatment effect compared to placebo, with a mean difference of 22.5 meters (95\% CI [4.0, 40.9]; $\mathrm{p}=0.0174$ ) between the two groups. Patients in the $2 \mathrm{mg} /$ kg QOW treatment group performed similarly to those in the placebo group.

The pharmacokinetics of elosulfase alfa at 2 $\mathrm{mg} / \mathrm{kg}$ were evaluated in 23 patients with MPS IVA who received IV infusions of VIMIZIM QW for 22 weeks. Following a single IV infusion at Week 0, elosulfase alfa plasma concentrations rapidly declined with a mean $t_{1 / 2}$ of 7.5 minutes. After repeated dosing, mean $t_{1 / 2}$ increased from
7.5 min to 35.9 min and mean $\mathrm{AUC}_{0-\mathrm{t}}$ and $\mathrm{C}_{\text {max }}$ increased to 2.8- and 2.9-fold, respectively, at Week 22. These changes may be related to the development of neutralizing antibodies (NAb) that are capable of inhibiting the drug from binding to the M6PR. Binding to this receptor is required for VIMIZIM to be taken into the cells where it is active.

All patients treated with VIMIZIM $2 \mathrm{mg} / \mathrm{kg}$ QW in the placebo-controlled trial developed anti-drug antibodies (ADA) by Week 4. ADA titers were either sustained or increased for the duration of VIMIZIM treatment. Because all patients developed ADA, associations between ADA titers and treatment effect could not be determined. In addition, all patients were positive for $\mathrm{NAb}$ at least once during the trial. Since $\mathrm{NAb}$ titers were not determined in these patients, the possibility of an association between NAb titers and treatment effect could not be assessed.

In clinical trials, the most common adverse reactions $(\geq 10 \%)$ observed included pyrexia, vomiting, headache, nausea, abdominal pain, chills, and fatigue. Forty-four of 235 (18.7\%) patients treated with VIMIZIM experienced hypersensitivity reactions, including anaphylaxis. Eighteen of $235(7.7 \%)$ patients experienced signs and symptoms consistent with anaphylaxis. The anaphylactic reactions occurred as early as 30 minutes from the start of and up to three hours after VIMIZIM infusion. Anaphylaxis occurred as late into treatment as the 47 th infusion.

Full prescribing information is available at: http: / / www.accessdata.fda.gov/drugsatfda docs/label/2014/125460s000lbl.pdf

By Christine Yuen-Yi Hon, PharmD, Clinical Pharmacology Reviewer and Yow-Ming Wang, PhD, Biologics Team Leader, Division of Clinical Pharmacology III, Office of Clinical Pharmacology, Office of Translational Sciences, CDER, FDA 